\title{
Electroacoustic miniaturized DNA-biosensor
}

\section{Jean Gamby, ${ }^{* a}$ Mathieu Lazerges, ${ }^{c}$ Christine Pernelle, ${ }^{c}$ Hubert Perrot, ${ }^{a}$ Hubert H. Girault ${ }^{b}$ and Bernard Tribollet $^{a}$}

Received 24th May 2007, Accepted 12th July 2007

First published as an Advance Article on the web 6th August 2007

DOI: $10.1039 / \mathrm{b} 707881 \mathrm{a}$

A micrometer-sized electroacoustic DNA-biosensor was developed. The device included a thin semi-crystalline polyethylene terephthalate (PET) dielectric layer with two Ag microband electrodes on one side and a DNA thiol-labeled monolayer adsorbed on a gold surface on the other. A resonance wave was observed at $29 \mathrm{MHz}$ with a network analyzer, upon AC voltage application between the two Ag electrodes, corresponding to electromechanical coupling induced by molecular dipoles of the PET polymer chain in the dielectric layer. It was found that the device size and geometry were well adapted to detect DNA hybridization, by measuring the capacity of the resonance response evolution: hybridization induced polarization of the dielectric material that affected the electromechanical coupling established in the dielectric layer. The $0.2 \mathrm{~mm}^{2}$ sensor sensitive area allows detection in small volumes and still has higher detection levels for bioanalytical applications, the non-contact configuration adopted avoids electric faradic reactions that may damage biosensor sensitive layers, and finally, PET is a costless raw material, easy to process and well adapted for large scale production. The well-balanced technological and economic advantages of this kind of device make it a good candidate for biochip integration.

Since the first use of a quartz monocrystal as a mass sensor in $1959,{ }^{1}$ acoustic piezo-electric devices have been intensively developed as physical, chemical and biochemical mass sensors. Their success is due to direct quantification of interfacial reactions by frequency measurements in the nano-pico gram range. Moreover, these sensors are label free, which is an advantage for bioanalytical applications. ${ }^{2-7}$ Nevertheless, a severe limitation, especially in gene diagnosis development, is the millimetric dimension of the piezo monocrystal which is too large and does not allow integration of such devices in biochips. We report in this letter, resonance of dielectric relaxation in semi-crystalline plastic ${ }^{8,9}$ in the high frequency domain, a unique and non-quantified phenomenon, and its application through a miniaturized contactless acoustic DNAbiosensor. Beyond the fundamental interest of the physical phenomenon involved, the designed device is a promising tool to transfer electroacoustic sensors towards biochip technologies.

The sensitive area of the dielectric device is composed of a gold covered semi-crystalline polyethylene terephthalate (PET) sheet, including two microelectrodes in a contactless configuration, as shown in Scheme $1 .^{10,11}$ This device was obtained from photoablation of a $100 \mu \mathrm{m}$ PET (melinex) sheet using a UV excimer laser (193 nm Argon Fluor Lambda Physik LPX 2051), in order to get a $10 \mu \mathrm{m}$ depth disk with a $2 \mathrm{~mm}$

${ }^{a}$ Laboratoire Interfaces et Systèmes Electrochimiques, UPR 15 CNRS, Casier 133, Université Pierre et Marie Curie, Paris 6, 4 place Jussieu, 75252, Paris Cedex 05, France.E-mail: gamby@ccr.jussieu.fr; Fax: +33 0144274074; Tel: +33 0144274324

${ }^{b}$ Laboratoire d'Electrochimie Physique et Analytique, Ecole

Polytechnique Fédérale de Lausanne, Faculté des Sciences de Base,

Institut des Sciences et Ingénierie Chimiques, 1015, Lausanne, Suisse

${ }^{c}$ Laboratoire de Génie Analytique, EA 4131, Conservatoire National des Arts et Métiers, 292 rue Saint Martin, 75141, Paris Cedex 03, France diameter. ${ }^{12}$ On the other side of the PET film, two parallel microchannels $50 \mu \mathrm{m}$ deep and $100 \mu \mathrm{m}$ wide were photoablated. The two channels were then filled with a commercial silver paste (ED3000 Electra Polymers). Another PET film was laminated on the face of the PET film, which included the two Ag electrodes, by heating at $60{ }^{\circ} \mathrm{C}$ for $4 \mathrm{~h}$. A thin $15 \mathrm{~nm}$ gold layer was deposited by DC plasma sputtering on the PET disk. The sensitive device surface was $0.2 \mathrm{~mm}^{2}$. The microchip was mounted inside a cylindrical home-made Teflon cell. The gold coated face was in contact with the cell solution.

A classic piezo-electric acoustic device was designed as a reference system to compare the performance of the dielectric device developed: ${ }^{13}$ an AT-cut planar piezo-electric quartz crystal (Matel-Fordhal), $14 \mathrm{~mm}$ in diameter and $1 \mathrm{~mm}$ thick with a $9 \mathrm{MHz}$ nominal resonance frequency was covered with two identical gold electrodes, $2000 \AA$ thick and $5 \mathrm{~mm}$ in diameter with a $250 \AA$ chromium underlayer. The sensitive

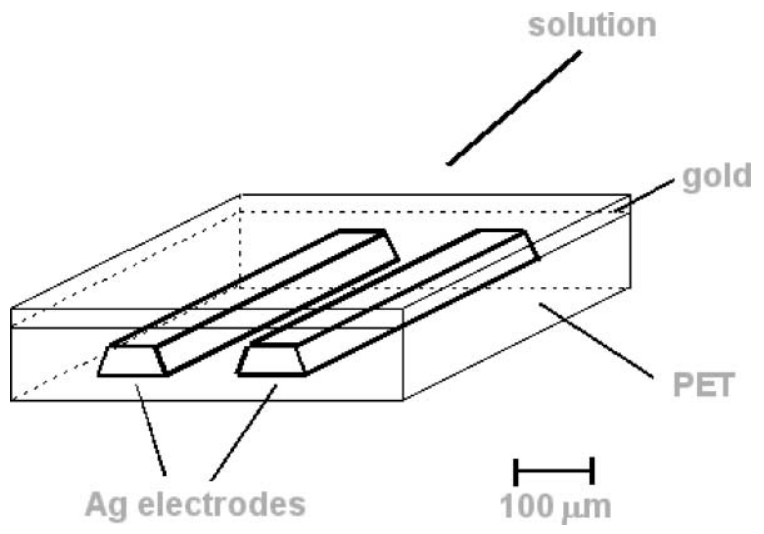

Scheme 1 Sensitive area of the contactless dielectric PET device. 
device surface was $19.6 \mathrm{~mm}^{2}$. The quartz crystal was mounted between two O-ring seals inserted in a home-made Plexiglass cell. One gold-coated face was in contact with the cell solution. The apparatus included a Pharmacia micropump to assure a constant flow of the solutions in the quartz cell.

Electrodes of both piezo-electric quartz and dielectric PET were connected through wires by a silver conducting paste to a network analyzer (HP 4194A), to apply frequency and record admittance. All the experimental set-up was computercontrolled through home-made software under HP-VEE ${ }^{\mathbb{R}}$ language. Electrical admittance measurements were performed with a $10 \mathrm{mV}$ perturbation signal at 201 frequencies around the resonance.

Resonance phenomena on both piezo-electric quartz and dielectric PET devices in a $10^{-2} \mathrm{M} \mathrm{MgCl}_{2}$ aqueous solution were observed, as shown in Fig. 1. The resonance of the dielectric device occurs at the same frequency range as the
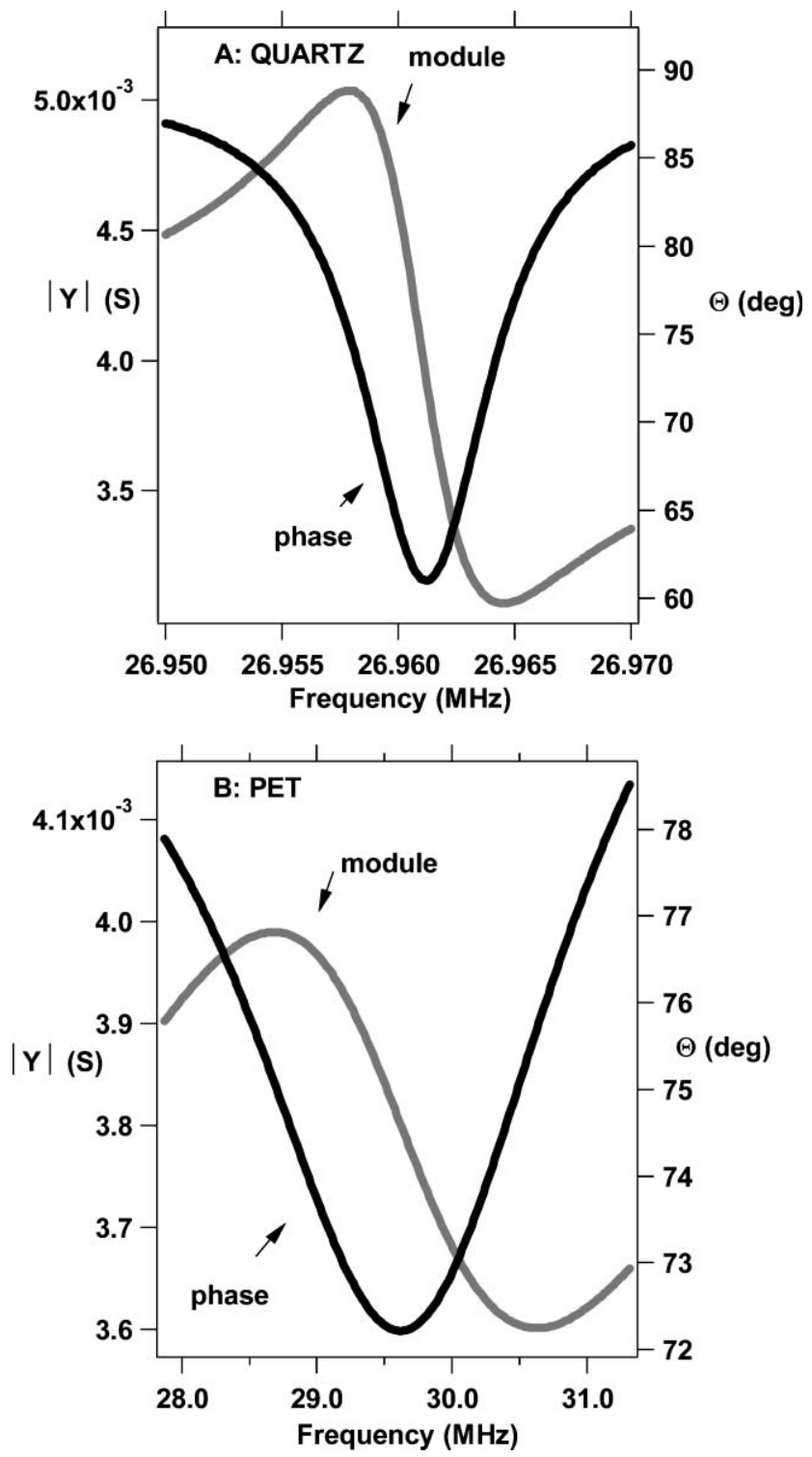

Fig. 1 Admittance modulus and the phase angle versus frequency of piezo-electric quartz (A) and semi-crystalline PET (B). piezo-electric quartz ones but is less accurate: the resonance width is $3 \mathrm{MHz}$ for semi-crystalline PET versus $0.02 \mathrm{MHz}$ for piezo-electric quartz. The motional region has inductive $L$, capacitive $C$ and resistive elements $R$. Theoretical fit using $R L C$ series for both resonator systems, yield to $R=0.509 \mathrm{k} \Omega$, $L=12.6 \mathrm{mH}, C=0.0276 \mathrm{pF}$ for the piezo-electric quartz crystal and $R=1.45 \mathrm{k} \Omega, L=78.8 \mu \mathrm{H}, C=0.368 \mathrm{pF}$ for the dielectric PET. Semi-crystalline PET include molecular dipoles
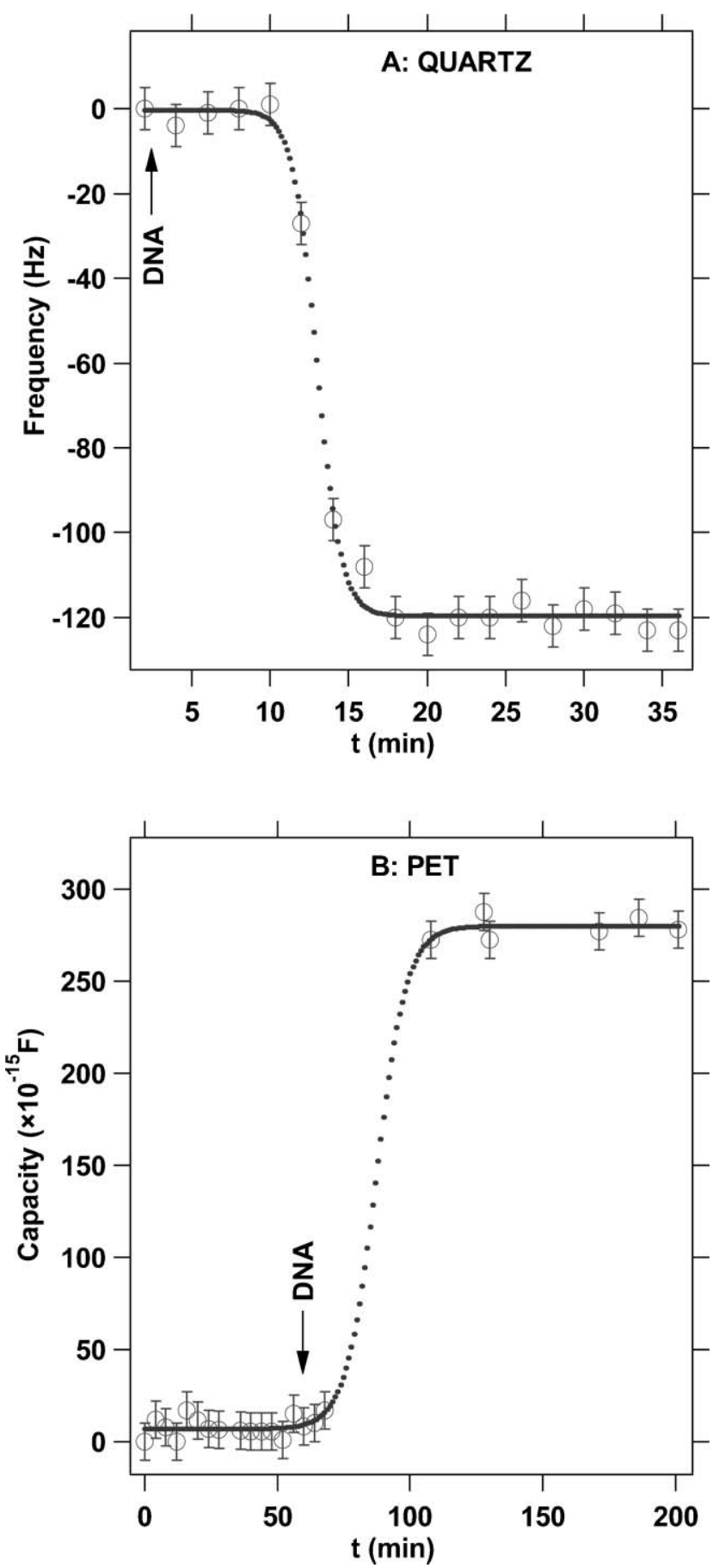

Fig. 2 Real time DNA hybridization monitored on frequency scale with piezo-electric quartz (A) and on capacity scale with semicrystalline PET (B) (frequency and capacity are variation relative to values at $t=0$ ). 
resulting from the molecular structure of the polymer chain. These dipoles give to the material, electromechanical coupling properties on the macroscopic scale. ${ }^{8}$ The resonance phenomenon observed, not yet reported in this frequency range, is attributed to this electromechanical coupling. The second part of this letter deals with the investigation of this resonance wave as an analytical criterion, to design an acoustic DNAbiosensor in a microchip.

Chemicals supplied for the DNA-biosensor experiments were $\mathrm{MgCl}_{2}$ (Sigma Aldrich, biochemical grade) and two oligonucleotides (Eurogentec) purified and quantified by OD UV measurements: a 20 mer DNA thiol-labeled probe HS$\left(\mathrm{CH}_{2}\right)_{6}-5^{\prime}$-AGC ACT GAT GTG TAA GGG CT-3' and a 40 mer DNA target $3^{\prime}$-TCG TGA CTA CAC ATT CCC GAA GAA CTT TGT GCC TGG TTC C-5' that included a 20 base sequence complementary to the 20 mer probe sequence. Water used in all experiments was deionized and doubly distilled. DNA-biosensors were designed on both piezo-electric quartz ${ }^{14}$ and dielectric PET device by immersing the gold surface with a $10 \mu \mathrm{g} \mathrm{mL} \mathrm{m}^{-1}$ thiol-labeled DNA probe solution in $10^{-2} \mathrm{M} \mathrm{MgCl}_{2}$ during two hours. After chemical grafting of the DNA-probe, electroacoustic measurements versus time were performed on both devices during addition of a $20 \mu \mathrm{g} \mathrm{mL}{ }^{-1}$ DNA-target solution in $10^{-2} \mathrm{M} \mathrm{MgCl}_{2}$. Piezoelectric DNA-biosensor frequency deduced from electroacoustic measurements is presented in Fig. 2A: the frequency decrease is attributed to mass increase, subsequent to the introduction of DNA-target hybridization on the biosensor surface. For the dielectric PET device, it appears after a data treatment that $C$ deduced from a $R L C$ fitting of the electroacoustic behavior around the resonance is the most interesting value to monitor the hybridization reaction: corresponding capacity variation presented on Fig. 2B indicates a $C$ increase, subsequent to DNA-target solution addition. The signal to noise ratio is equal to 20 for the two devices, showing that hybridization detection on the dielectric PET sensor is as stable as on the piezo-electric quartz sensor. We studied the electroacoustic resonance response during DNA hybridization on the gold-covered PET surface. We found that the capacity of the resonant model response was well adapted to monitor DNA hybridization. We attribute the capacity variation to PET polarization changes, subsequent to modification of the space charge region solution due to DNA hybridization. In other words, the device size and geometry are well adapted to detect modification of an electromechanical PET response, subsequent to the modification of the PET polarization. This method is fundamentally different from direct measurement of capacity surface by electric impedance measurements. Its interest lies in a non-contact configuration that avoids electric faradic reactions that may damage biosensor sensitive layers.

Full investigations of this DNA-biosensor in terms of detection limit, selectivity and a detailed physical model of the response around the resonance will be presented in a subsequent study. These first experiments demonstrate that the dielectric semi-crystalline PET device designed, enables us to detect interfacial hybridization by measuring capacity variation of the $R L C$ resonant circuit, as it is possible with a piezo-electric quartz sensor by following frequency changes. The PET sensor sensitive area $\left(0.2 \mathrm{~mm}^{2}\right)$ is 100 times smaller than the quartz sensor one $\left(19.6 \mathrm{~mm}^{2}\right)$. It allows detection in a small volume and still has a higher detection level for bioanalytical applications. Another advantage is the noncontact configuration adopted. Finally, PET is a costless raw material, easy to process and well adapted for large scale production. The well-balanced technological and economic advantages of this kind of device make it a good candidate for biochip integration. ${ }^{15-17}$

We wish to thank Valérie Devaud (LEPA, EPFL) for her technical help, and the European Science Foundation through action "COST D33" for financial support.

\section{References}

1 G. Sauerbrey, Z. Phys., 1959, 155, 206-222.

2 M. D. Ward and D. A. Buttry, Science, 1991, 251, 1372.

3 M. A. Cooper, F. N. Dultsev, T. Minson, V. P. Ostanin, C. Abell and D. Klenerman, Nat. Biotechnol., 2001, 19, 833-837.

4 F. Patolsky, A. Lichtenstein and I. Willner, J. Am. Chem. Soc., 2000, 122, 418-419.

5 M. D. Ward and D. A. Buttry, Science, 1991, 251, 1372.

6 B. Godber, K. S. J. Thompson, M. Rehak, Y. Uludag, S. Kelling, A. Sleptsov, M. Frogley, K. Wiehler, C. Whalen and M. A. Cooper, Clin. Chem., 2005, 51, 1962-1972.

7 G. Steve Huang, M.-T. Wang and M.-Y. Hong, Analyst, 2006, 131, 382-387.

8 C. Bucci, R. Fieschi and G. Guidi, Phys. Rev., 1966, 148, 816-823.

9 E. Neagu, P. Pissis, L. Apekis and J. L. Gomez Ribelles, Phys. D: Appl. Phys., 1997, 30, 1551-1560.

10 J. Gamby, J.-P. Abid and H. H. Girault, J. Am. Chem. Soc., 2005, 127, 13300-13304.

11 J. Gamby, J.-P. Abid, M. Abid, J.-P. Ansermet and H. H. Girault, Anal. Chem., 2006, 78, 5289-5295.

12 M. A. Roberts, J. S. Rossier, P. Bercier and H. H. Girault, Anal. Chem., 1997, 69, 2035-2042.

13 K. Bizet, C. Gabrielli and H. Perrot, Appl. Biochem. Biotechnol., 2000, 89, 139-149.

14 M. Lazerges, H. Perrot, N. Rabehagasoa, E. Antoine and C. Compere, Chem. Commun., 2005, 48, 6020-6022.

15 J. W. Hong and S. R. Quake, Nat. Biotechnol., 2003, 21, $1179-1183$.

16 H. Wu, J. Zhai, Y. Tian, H. Lu, X. Wang, W. Jia, B. Liu, P. Yang, Y. Xu and H. Wang, Lab Chip, 2004, 4, 588-597.

17 M. S. Wilson and W. Nie, Anal. Chem., 2006, 78, 6476-6483. 